Mortality of tobacco abuse patients was compared by logistic regression. $\mathrm{P}$ values of $<0.05$ were taken as statistically significant.

Results 28379 patients had comorbid tobacco abuse during the study period. Mean age of tobacco abusers was 44.9 years, $51.2 \%$ were male and $1918(6.8 \%)$ tobacco abuse patients died. The majority were Caucasian $(84.8 \%)$ with lower proportions of South Asian (4.7\%), Afro-Caribbean (1.9\%), Oriental $(0.2 \%)$, mixed (1.0\%), other $(2.5 \%)$ and unknown $(4.8 \%)$ ethnicities. Crude mortality was highest amongst Caucasian patients $(7.3 \%)$ compared to South Asian (2.2\%), AfroCaribbean (2.7\%), Oriental (1.7\%), mixed (0.3\%), other (3.1\%) and patients with unknown ethnicities (6.1\%). Of all these ethnic groups, logistic regression accounting for age and sex showed that only South Asian ethnic origin affected mortality rates amongst patients with comorbid tobacco abuse. South Asian patients were 1.90 times more likely to die $\mathbf{9 5 \%}$ CI 1.21-2.97).

Conclusion Our results demonstrate that mortality of tobacco abusers varies according to ethnicity with higher mortality amongst South Asian patients in particular. This could represent differences in smoking rates or an increased susceptibility to smoking. This is particularly important given that smoking and South Asian ethnicity are both known risk factors for developing cardiovascular disease.

\section{HYPERLIPIDAEMIA REDUCES MORTALITY IN BREAST, PROSTATE, LUNG AND BOWEL CANCER}

${ }^{1}$ Paul R Carter*, ${ }^{2}$ John Mcgowan, ${ }^{3}$ Hardeep Uppal, ${ }^{4}$ Suresh Chandran, ${ }^{5}$ Jaydeep Sarma, ${ }^{3}$ Rahul Potluri. ${ }^{1}$ The Royal Free London NHS Foundation Trust; ${ }^{2}$ Central Manchester University Hospitals NHS Foundation Trust; ${ }^{3}$ ACALM Study Unit in Collaboration with Aston Medical School; ${ }^{4}$ Department of Acute Medicine, North Western Deanery; ${ }^{5}$ University Hospital South Manchester, *Presenting Author

10.1136/heartjnl-2016-309890.79
Introduction Hyperlipidaemia is a well -established cardiovascular risk factor but the effect of hyperlipidaemia and treatment with cholesterol-lowering drugs on cancer remain equivocal. We aimed to investigate the impact of comorbid diagnosis of hyperlipidaemia amongst patients with the four most prevalent cancer types in the United Kingdom (Lung, Breast, Prostate and Bowel). We did this using a large database of patients admitted with comorbid hyperlipidaemia to hospitals in the North of England, UK between 2000-2013.

Methods Anonymous information on patients with a primary diagnosis of lung, breast, prostate and bowel cancers were obtained from hospitals in North England, UK between $1^{\text {st }}$ January 2000 and $31^{\text {st }}$ March 2013. This data was analysed according to the ACALM (Algorithm for Comorbidities, Associations, Length of stay and Mortality) study protocol. ICD-10 and OPCS-4 codes were used to trace patients coded for cancer, patient demographics, prevalence of hyperlipidaemia and mortality data. The impact of hyperlipidaemia on mortality in cancer patients was analysed by cox regression adjusted for age, gender and ethnicity. $\mathrm{P}$ values of $<0.05$ were taken as statistically significant.

Results 929552 patients were admitted during the study period. Of these 7997 had lung cancer, 5481 had breast cancer, 4629 had prostate cancer, and 4570 had bowel cancer. Comorbid diagnoses of hyperlipidaemia significantly reduced mortality amongst patients with all four cancer types studied. Cox regression analyses accounting for differences in age, gender and ethnicity showed that hyperlipidaemia was associated with a significantly reduced mortality rate in lung cancer (OR 0.78, 95\% CI 0.70-0.87), breast cancer (OR 0.57, 95\% CI $0.43-0.77$ ), prostate cancer (OR $0.53,95 \%$ CI $0.50-0.79$ ) and bowel cancer (OR 0.70, 95\% CI 0.58-0.84).

Conclusion We have demonstrated for the first time that comorbid hyperlipidaemia has a highly protective effect on mortality amongst patients with the four most prevalent cancers in the UK. The underlying reasons for this are yet to be determined but treatment with statins may contribute. This

Abstract 78 Table 1 Demonstrates the crude unadjusted and the adjusted mortality rates for tobacco users according to ethnicity

\begin{tabular}{|c|c|c|c|}
\hline Ethnicity & $\begin{array}{c}\text { Prevalence } \\
\mathbf{n}(\%)\end{array}$ & $\begin{array}{c}\text { Crude mortality } \\
\mathbf{n}(\%)\end{array}$ & $\begin{array}{c}\text { Odds ratio } \\
\text { (95\% confidence } \\
\text { intervals) }\end{array}$ \\
\hline Caucasian & $24077(84.8 \%)$ & $1767(7.3 \%)$ & $0.80(\mathrm{Cl} 0.62-1.01)$ \\
\hline South Asian & $1334(4.7 \%)$ & $29(2.2 \%)$ & $1.90(\mathrm{Cl} 1.21-2.97){ }^{*}$ \\
\hline Afro-Caribbean & $546(1.9 \%)$ & $15(2.7 \%)$ & $1.48(\mathrm{Cl} 0.83-2.65)$ \\
\hline Oriental & $59(0.2 \%)$ & $1(1.7 \%)$ & $3.54(\mathrm{Cl} 0.47-26.99)$ \\
\hline Mixed & $293(1.0 \%)$ & $1(0.3 \%)$ & $5.85(\mathrm{Cl} 0.80-42.63)$ \\
\hline Other & $719(2.5 \%)$ & $22(3.1 \%)$ & $1.25(\mathrm{Cl} 0.75-2.06)$ \\
\hline Unknown & $1351(4.8 \%)$ & $83(6.1 \%)$ & \\
\hline
\end{tabular}

$\mathrm{p}<0.05^{*}$ 
Abstract 79 Table 1 Odds ratio adjusted for age, gender and ethnicity

\begin{tabular}{|c|c|c|c|c|c|}
\hline $\begin{array}{c}\text { Cancer } \\
\text { Type }\end{array}$ & $\begin{array}{c}\text { Prevalence } \\
\text { of Cancer } \\
\mathbf{n}\end{array}$ & $\begin{array}{c}\text { Prevalence of } \\
\text { Hyperlipidaemia } \\
\mathbf{n}(\%)\end{array}$ & $\begin{array}{c}\text { Crude mortality } \\
\text { with } \\
\text { Hyperlipidaemia } \\
\mathbf{n}(\%)\end{array}$ & $\begin{array}{c}\text { Crude mortality } \\
\text { without } \\
\text { Hyperlipidaemia } \\
\mathbf{n}(\%)\end{array}$ & $\begin{array}{c}\text { Adjusted Odds } \\
\text { ratio for } \\
\text { Mortality } \\
\mathbf{( 9 5 \%} \text { CI) }\end{array}$ \\
\hline $\begin{array}{c}\text { Lung } \\
\text { Cancer }\end{array}$ & 7997 & $473(5.9 \%)$ & $383(81.0 \%)$ & $6521(86.7 \%)$ & $\begin{array}{c}0.78 \\
(0.70-0.87)^{* * * *}\end{array}$ \\
\hline $\begin{array}{c}\text { Breast } \\
\text { Cancer }\end{array}$ & 5481 & $170(3.1 \%)$ & $47(27.6 \%)$ & $1962(36.9 \%)$ & $\begin{array}{c}0.57 \\
(0.43-0.77)\end{array} * * *$ \\
\hline $\begin{array}{c}\text { Prostate } \\
\text { Cancer }\end{array}$ & 4629 & $271(5.9 \%)$ & $74(27.3 \%)$ & $2042(46.9 \%)$ & 0.53 \\
\hline $\begin{array}{c}\text { Bowel } \\
\text { Cancer }\end{array}$ & 4570 & $243(5.3 \%)$ & $125(51.4 \%)$ & $2716(62.8 \%)$ & $\begin{array}{c}0.70 \\
(0.50-0.79) * * *\end{array}$ \\
\hline
\end{tabular}

$p<0.05^{*} \quad p<0.01^{*} \quad p<0.001 \quad \mathrm{Cl}=$ Confidence Intervals

potentially beneficial effect of lipid-lowering medications amongst cancer patients should be further investigated.

\section{TWO YEAR PROGNOSIS IN STABLE CORONARY ARTERY DISEASE: A PROSPECTIVE STUDY OF 2346 PATIENTS IN UK PRIMARY CARE}

${ }^{1}$ Michael Pope*, ${ }^{2}$ Nicola Greenlaw, ${ }^{2}$ lan Ford, ${ }^{3}$ Gabriel Steg, ${ }^{3}$ Kim Fox, ${ }^{4}$ Paul Kalra. ${ }^{1}$ Portsmouth Hospitals NHS Trust; ${ }^{2}$ Robertson Centre; ${ }^{3} \mathrm{NHLI}$ Imperial College; ${ }^{4}$ Portsmouth Hospital NHS Trust and NHLI Imperial College; *Presenting Author

\subsection{6/heartjnl-2016-309890.80}

Introduction Coronary artery disease (CAD) is a leading cause of morbidity and mortality in the UK. Whilst data are available on outcomes for patients with acute coronary syndromes, much less is known about mortality and other cardiovascular outcomes for outpatients with stable CAD managed predominantly in primary care. CLARIFY (the "ProspeCtive observational LongitudinAl Registry oF patients with stable coronarY artery disease") is a large international study that provides a unique opportunity to describe the contemporary characteristics and outcomes for patients with stable CAD in the UK and compare them with a worldwide population.

Methods CLARIFY is an international, prospective, observational, longitudinal study designed to collect data on the characteristics, management and outcomes of patients with stable CAD. Patients were enrolled between November 2009 and June 2010 from an outpatient population with a history of at least one of the following: myocardial infarction (MI), coronary artery bypass grafting (CABG), or percutaneous coronary intervention (PCI) $>3$ months prior to recruitment; coronary stenosis. $>50 \%$; or reversible myocardial ischemia.

Enrollment occurred across 45 countries. To reduce selection bias, each participating physician recruited 10-15 consecutive outpatients with CAD to meet a predefined country target of 25 patients per million inhabitants (range 12.5-50). In the UK, patients were recruited from 250 GP surgeries, selected to provide a geographic and socioeconomic profile representative of the population. Baseline data included demographics, clinical history, risk factors and drug therapy. Patients are followed up for 5 years with annual assessments to assess clinical status, outcomes and medications and 6-monthly telephone calls
An independent centre, the Robertson Centre for Biostatistics at the University of Glasgow, was responsible for data collection and analysis.

Results 32,901 patients were recruited worldwide, of which 2,346 were from the UK and form this study population. Table 1 outlines the baseline characteristics as compared to the rest of the CLARIFY population. Mean age was $67 \pm 9$ years in the UK (rest of CLARIFY $63.9 \pm 10.5, \mathrm{p}<0.001$ ) and around $3 / 4$ were male. Significant co-morbidities were common, together with a high prevalence of cardiovascular risk factors $(18 \%$ with diabetes and $70 \%$ with a history of smoking in the UK). Although MI was more common there was a significantly lower prevalence of heart failure in the UK cohort.

At 2 year follow-up all cause mortality was $3 \%$ and cardiovascular mortality $1.3 \%$.

Conclusions In a large, representative cohort of stable CAD patients in primary care within the UK 2-year mortality is $3 \%$ and is similar to that seen in the rest of the international CLARIFY population. Secondary prevention appears to be reasonable although there may be room for improvement. Although there appear to be differences in rates of MI and stroke, further analysis is needed to explore the possible causes for these.

\section{INNOVATIVE MANAGEMENT OF LOW RISK PATIENTS WITH CHEST PAIN PRESENTING TO THE EMERGENCY DEPARTMENT}

Michael Pope, Nichola Pugh*, Thomas Gilpin, Tom Farrell. Portsmouth Hospitals NHS Trust; *Presenting Author

\subsection{6/heartjnl-2016-309890.81}

Introduction Chest pain is one of the most common symptoms amongst patients presenting acutely to secondary care. The Rapid Access Cardiology Clinic (RACC) was established at our hospital with the aim of reducing admissions of low risk patients presenting to the emergency department (ED) and medical assessment unit (MAU) with chest pain of presumed cardiac origin. This is designed as a 'next day' consultant led service running 5 days a week with access to same day echocardiography, invasive and CT coronary angiography. This evaluation aimed to assess safety, clinical outcomes and service efficiencies achieved from this service. 